\title{
AC 2008-501: INTERDISCIPLINARY TEACHING TECHNIQUES AND LEARNING IN DYNAMIC MODELING AND CONTROL
}

\section{Robert Rabb,}

David Chang, United States Military Academy 


\title{
Interdisciplinary Teaching Techniques and Learning in Dynamic Modeling and Control
}

\begin{abstract}
Engineering education experiences unique challenges as well as opportunities. As the future of engineering education emphasizes more interdisciplinary work and more work performed in teams, one logical starting point for this evolution in interdisciplinary work is with the faculty. Engineering educators cannot ignore the real world's shifting focus to interdisciplinary engineering, and they should adapt as well. Similar to the total engineering process as a team effort, the engineering education process is equally a team effort with excellent communications between faculties from different departments. This paper highlights a classical dynamical modeling and controls course with students and instructors from different departments: electrical engineering and mechanical engineering. The role of course director rotates between the two departments each semester with shared responsibilities throughout the semester between the instructors. This organizational structure is important, allowing the interdisciplinary faculty team to synchronize their efforts, bringing their individual strengths and resources together for the course to promote student learning. The instructors engage in meaningful dialogue concerning their assignments, lesson preparations, laboratory exercises, and their results. The information flow between instructors from different departments encourages faculty learning by pushing the instructors beyond their own discipline. This paper illustrates some of the course details employed between two engineering departments to advance and enrich an interdisciplinary controls engineering course. Advantages to empowering an interdisciplinary faculty are also described. The techniques described allow the students to benefit from the work of an interdisciplinary faculty team and enrich the students' understanding by bringing in real world projects and examples, elucidated by discipline specific instructors, to academic settings.
\end{abstract}

\section{Introduction}

Recently the National Academy of Engineering developed a publication "Educating the Engineer of 2020", which mentioned many ideas of co-teaching, just in time teaching, and multidisciplinary teaching. Industry and various academic institutions feel that it is vital to integrate engineering because most systems existing presently are developed with integrated engineering teams ${ }^{1}$. Drexel University (Philadelphia, PA) proposed and was awarded National Science Foundation funds in 1987 to develop an Enhanced Experience for Engineering Education (E4) ${ }^{2}$. This program integrated students and faculty from all engineering disciplines for the first two years of the student's engineering education and put them through an intense integration experience. This program was designed to attract many more students to engineering; however, due to its significant attrition rate (an average 60\%), this is one of the reasons why Drexel University is planning to stop the program next year. However, our approach is very different. Instead of integrating the students in the freshman and sophomore years, we are integrating them in the senior year. The advantage is that the students are much more developed in their engineering discipline and we are adding to that knowledge base. 
The analysis and design of feedback systems have drawn several disciplines closer together over the decades. It is not difficult to find a mechanical system that has an electrical analogy and vice versa. This natural equivalence between these two disciplines has allowed a single course to evolve concerning the theory and fundamentals of control systems engineering. Requiring the students to see a broader picture across several disciplines also requires the instructors to change their discipline specific practices.

Integral to the education of its engineering graduates, the United States Military Academy (USMA) ensures all of its engineering graduates take a set of engineering courses to develop their problem solving skills and expose them to technology in society. The academic program, like the other aspects of the USMA environment, is designed to promote development in a wide variety of traditional subjects in the sciences essential to future military service. Two departments at USMA have fostered an interdisciplinary, senior level course of control systems engineering with broad applications to mechanical and electrical systems. In order to create an interdisciplinary engineering experience, the students must know some basic laws and fundamentals of engineering, necessary to engage in practical application of the subject matter. This knowledge comes from several engineering courses taught usually during their junior year: Introduction to Electrical Engineering, Engineering Mathematics, and Dynamics. These courses are also taught by different departments and the faculties are single-disciplined.

This paper will focus on and examine the course, Dynamic Modeling and Control, required at USMA of all mechanical engineers and for the electrical engineers that are in the robotics track. Although the course uses a standard textbook and covers many classical and some modern control topics, it is different in some ways from a typical engineering course. The course is taught with students from the two disciplines mixed within each section. Instructors are from two different departments and use a team-teaching approach to administer, teach, and improve the interdisciplinary course. Team-teaching usually involves discipline specific instructors teaching their area of expertise to the students. This course differs in that each instructor, regardless of a mechanical or electrical background, teaches all lessons to his section that is mixed with both mechanical and electrical engineering students. Perhaps the most obvious difference is that the course director changes between departments each semester. Additionally, various outcomes from the course and insights gained from the instructors will be presented. Although the course has been taught for several years, this is the first time to assess the effectiveness of the administrative model and structure of the course. Future terms are expected to corroborate the material presented in this paper.

\section{Background}

The Dynamic Modeling and Control course devotes 3.0 credit hours to engineering topics with 2.0 credit hours allotted to engineering science and 1.0 credit hour to engineering design. The course builds upon the foundations from the basic engineering mechanics course in statics and dynamics, and the basic electrical engineering course covering electrical circuits and components. The course provides the background, experience, and fundamental design knowledge to complete capstone design projects requiring dynamic modeling and control expertise. The course is multidisciplinary and is conducted as a joint offering with the 
Department of Electrical Engineering and Computer Science and the Department of Civil and Mechanical Engineering.

Presently about $80 \%$ of the students taking the course are Mechanical Engineering students and $20 \%$ are Electrical Engineering Students. Table 1 below correlates sample electrical engineering program outcomes to the course content using the following scale:

1=No contribution; $2=$ Small contribution; $3=$ Average contribution; 4=Large contribution; $5=$ Very large contribution

Table 1. Relationship of Course to Electrical Engineering Program Outcome

\begin{tabular}{|c|c|}
\hline ELECTRICAL ENGINEERING PROGRAM OUTCOMES & $\begin{array}{c}\text { COURSE } \\
\text { DIRECTOR } \\
\text { ASSESSMENT }\end{array}$ \\
\hline $\begin{array}{l}\text { 1. Apply knowledge of mathematics, probability, statistics, physical science, } \\
\text { engineering, and computer science to the solution of problems. [ABET Criterion } 3 \\
\text { Outcome (a)] }\end{array}$ & 4.5 \\
\hline $\begin{array}{l}\text { 2. Identify, formulate, and solve electrical engineering problems. [ABET Criterion } 3 \\
\text { Outcome (e)] }\end{array}$ & 4 \\
\hline $\begin{array}{l}\text { 3. Apply techniques, simulations, information and computing technology, and } \\
\text { disciplinary knowledge in solving engineering problems. [ABET Criterion } 3 \text { Outcome } \\
\text { (k)] }\end{array}$ & 4 \\
\hline $\begin{array}{l}\text { 4. Design and conduct experiments to collect, analyze, and interpret data with modern } \\
\text { engineering tools and techniques. [ABET Criterion } 3 \text { Outcomes (b) and (k)] }\end{array}$ & 4 \\
\hline $\begin{array}{l}\text { 5. Communicate solutions clearly, both orally and in writing. [ABET Criterion } 3 \\
\text { Outcome }(\mathrm{g}) \text { ] }\end{array}$ & 4 \\
\hline 6. Work effectively in diverse teams. [ABET Criterion 3 Outcome (d)] & 3 \\
\hline $\begin{array}{l}\text { 7. Apply professional and ethical considerations to engineering problems. [ABET } \\
\text { Criterion } 3 \text { Outcome }(\mathrm{f}) \text { ] }\end{array}$ & 3 \\
\hline $\begin{array}{l}\text { 8. Incorporate understanding and knowledge of societal, global and other contemporary } \\
\text { issues in the development of engineering solutions that meet realistic constraints. } \\
\text { [ABET Criterion } 3 \text { Outcomes (c), (h) and (k)] }\end{array}$ & 4 \\
\hline Demonstrate the ability to learn on their own. [ABET Criterion 3 Outcome (i)] & 3 \\
\hline
\end{tabular}

The course provides an overview of classical control theory as the foundation for control applications in electrical, mechanical, chemical and aeronautical systems. Topics here include system modeling using Laplace transform, frequency domain, and state variable methods. Mathematical models are developed for electrical, mechanical, aeronautical, and other physical control systems. Control systems analysis and design techniques are studied within the context of how each system is physically controlled in practice. Laboratory exercises include feedback 
design and system identification. Computer design exercises include dynamic modeling and control of various engineering systems. The course learning objectives are:

1. Model the dynamics of various physical systems that include mechanical and electrical components.

2. Analyze a physical system that utilizes a control system and determine its ability to meet performance specifications for stability, steady-state error, and transient response.

3. Design a controller for a physical system to meet a set of performance specifications using Root Locus, Frequency Response, and State-Space methods.

4. Connect and integrate topics from Thermodynamics, Statics, Dynamics, CAD, Fluids, Vibrations, EE Fundamentals, Circuit Theory, Basic Electronics, Linear System Theory, and/or Signal Representation Techniques.

\section{Advantages}

The engineering curriculum at USMA attempts to bring real world experiences for the student, and part of this includes integrating various engineering disciplines. It is highly encouraged to have interdisciplinary senior design teams and projects, because when the students leave the academic environment they are expected to work in diverse teams. So, this course gives the students an initial step to working with other faculty and students. The students are subjected to an interdisciplinary course and the faculty must portray it as a subject with value beyond a specific niche. This integration of teaching will bring various engineering subjects together as most presently developed systems are an integration of engineering such as a camera, automobile, space shuttle, and robot. In the course, students reinforce their discipline specific knowledge and integrate it with new knowledge and applications. This requires the faculty to understand and have some fluency in the other discipline. For example, each instructor conducts demonstrations and laboratories for his sections, regardless if the demonstration or laboratory exercise is electrical and the instructor is the mechanical engineer. Unlike some demonstrations in other engineering classes, sometimes a specific instructor must give the demonstration to all students taking the course.

USMA operates in a very collaborative environment, allowing open discussion between instructors of the two different departments to find better ways to present material that may not be specific to one's discipline. The quality of instruction improves as the instructors use their discipline specific strengths to address topics from different backgrounds. At the same time, an instructor confronted with a new or unfamiliar topic can learn and improve in a nonthreatening setting from peer instructors in the other discipline. Working together, it is relatively simple to find a different approach to present material or draw an analogy in another discipline. For instance, a mechanical system of masses, springs, and dampers can be represented with an electrical circuit of inductors, capacitors, and resistors. The mathematics to design a controller to meet specifications will be the same, but the students benefit from seeing the similarities in the physical models. This encourages innovation among the instructors to appeal to the different disciplines. Ideally, the students will see the continuities and similarities in different disciplines if the instructors have done their work to integrate the material. 
Perhaps an overlooked advantage to the interdisciplinary team teaching structure is that this organization allows an instructor to readily build upon student knowledge or a lecture presented in the other discipline. Constant dialogue between instructors of the two disciplines allows each to know what the students should know or retain. There are certain topics that electrical engineers know from their previous classes, and certain subjects all students should know from the required electrical engineering course. Rather than trying to determine the basic electrical engineering knowledge of the students, the mechanical engineering instructor knows the subjects and depth covered in the electrical engineering course. This collaboration allows the instructor to progress the material in a lesson without having to cover basic knowledge. Instructors can also draw on certain students' strengths during classroom discussions. Instructors are able to address learning techniques and study skills when familiar with the other discipline's basic knowledge.

Inherent in a course taught by multiple instructors is the obvious advantage of the shared workload for problem development, labs, grading, tests, and student advising. The instructor team sets the lessons' content to meet the course objectives, determines texts, videos, demonstrations, and supplemental materials. The individual instructors can use their initiative and department resources to develop or refine demonstrations and videos for the teaching team. It is essential that the strengths and weaknesses of the individual instructors are assessed in order to share the course workload. The flexible, collaborative environment allows for individuals to perform at their best. Using discipline specific equipment, the electrical engineer can develop an electrical engineering demonstration, the mechanical engineer can develop a mechanical engineering demonstration, and together the students see the same control design process and mathematics applied to different disciplines. Recently, for a lesson on frequency response design, a mechanical engineer instructor developed a demonstration with sound and visual effects that all the students could relate to their cars or other moving systems. The students appreciated the demonstration and had something to which they could relate future classes on controller design. The electrical engineer instructor did not have the same equipment in his department. Had the course been taught by one department or the other, numerous opportunities like this would be passed. Likewise, the electrical engineering instructor can more easily develop an electrical engineering problem for homework or a test than the mechanical engineer. By dividing the instructor workload, the team operates more efficiently. The instructors understand that the course director role, and thus the responsibility for administering the course, rotates between the departments, so assisting other instructors is advantageous to all concerned and keeps the instructors from the different departments engaged in the course. Additionally, the change also motivates the instructors to keep course notes current and grade consistently.

\section{Disadvantages}

It is well documented in general literature on interdisciplinary teaching that the greatest challenge for the instructors is the time and energy required to work as a team ${ }^{1-5}$. In this course of controls engineering with application to electrical and mechanical engineering, the instructors agree that time management demands skill and cite some specific examples. Scheduling meetings between faculties of two different departments is more difficult, but a committed teaching team can make it work. 
First, problem development requires understanding of the other instructor's methodology. Knowing how another instructor presents the material and how and what he expects the students to learn, ensures that problems developed for homework or tests are fair and relevant. This may require some standardization of the lesson material on which the instructors should agree. For instance, the use of specific mathematical identities, equations, or "shortcuts" presented by one instructor may be helpful in particular problems. However, a more general or universal methodology may take longer to solve but is applicable in more types of problems. The instructors should agree which method they expect the students to use and develop problems that reinforce the application.

Secondly, many of the concepts and objectives in control engineering such as stability and transient response are more visually and audibly demonstrated with mechanical engineering examples. Vibration demonstrations easily show resonance or natural frequency. Students usually like these intuitive demonstrations rather than observing a static screen or listening to the instructor describe a scenario. The use of these devices requires all of the instructors to be familiar with the equipment, can demonstrate their use without using up much class time, and be able to troubleshoot problems if they arise. The use of the equipment, like a lesson planning conference, requires additional time for the subject matter expert to demonstrate the equipment to all instructors. The use of highly visual mechanical demonstrations would seem to focus more controls design attention on mechanical rather than electrical applications. However, analogies are presented in electrical engineering when available or appropriate. Because interdisciplinary teaching takes additional time to understand another discipline, the instructors attempt to balance the demonstrations and the use of example applications.

Laboratories are the most difficult area for agreement between instructors. Similar to demonstrations, they require much time to ensure all instructors are familiar with the lab equipment and know the end state of the lab exercise. The laboratory equipment employs various electromechanical units and devices as examples of systems to examine. These units are designed for controls applications, but as most students taking controls for the first time, the subject is not readily intuitive. These lab setups are used to emulate actual systems so sometimes it is difficult for the students to relate between lab setups, mathematical equations and actual systems. However, these lab setups are still used due to the flexibility and low cost of electronic components, and mechanical laboratory equipment was rarely used. The high use of electronic equipment especially causes some initial apprehension with the mechanical engineers, for both instructor and students. Using a signal generator, an oscilloscope, and analogue feedback board are perishable skills for the mechanical engineer instructor. However, part of the experience for both instructors and students was to apply some of the course content to different disciplines.

The role of the course director changes from one department to the other each semester, allowing each department to have a more active role in course leadership and direction. Although this arrangement seems to work as an advantage, it also creates some administrative challenges. The course director usually must specify to the Dean's office each instructor's role and what administrative access each must have during the semester to conduct the course. Administrative offices around campus usually are ill-informed of whom to contact when it comes time for book orders, course decisions, etc. 


\section{Expected Outcomes and Assessment}

This course is primarily a lecture based course that attempts to cover a range of applications in mechanical and electrical engineering. The course starts by over viewing subject or discipline specific modeling of systems such as electrical, mechanical, rotational and electromechanical. Then the course progresses to generalizing each system and developing various methodologies to treat each system in a similar fashion. This is analogous to the pedagogy we use in classes. Although the instructors come from different backgrounds but could generalize the teaching, they educate a body of multidisciplinary students.

One of the instructors' goals was to assess the effectiveness of the interdisciplinary faculty structure. A look at the course feedback data from students taking the Dynamic Modeling and Control course shows some interesting and encouraging results. For the most part, the students agree that the course is a positive experience for them and is equal to or slightly better than other single discipline courses. Although different instructors taught the course over the academic year, individual instructor assessments were very close, so the overall course results are presented. Particular ratings that are addressed in the discussion are indicated on the graphs. The following scale (Table 2) was used for the students' survey:

Table 2: Assessment Scale

\begin{tabular}{|c|c|c|c|c|}
\hline 1 & 2 & 3 & 4 & 5 \\
\hline strongly disagree & disagree & neutral & agree & strongly agree \\
\hline
\end{tabular}

The following assessments address the objective ratings above. Student comments and discussion on the student surveys reinforce their overall ratings. Additionally, the rating scale is a normal set of responses used at USMA for student surveys. Students and faculty alike are familiar with the same standard set of responses and their interpretation.

Institution Level Questions

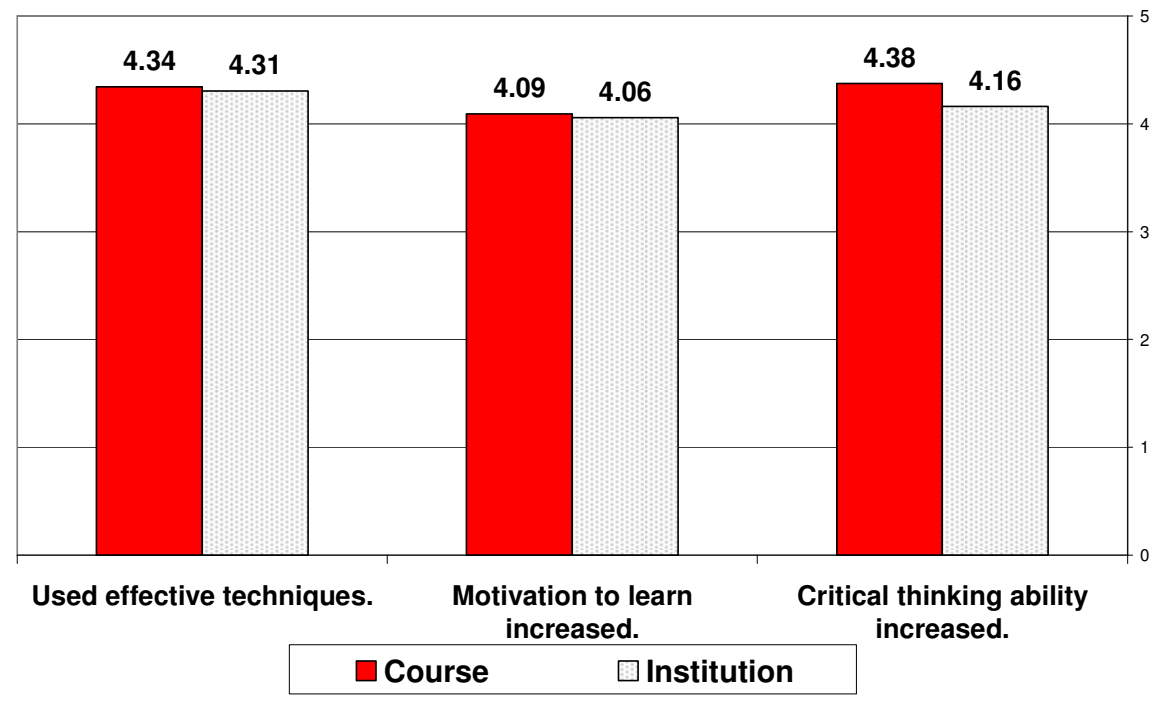

Figure 1. Institution Level Survey Questions 
It can be seen from Figure 1 that the students felt effective techniques were used in the course which resulted in a slightly higher average than the institution. The previously mentioned collaborative environment among the faculty lends to better instruction and techniques than teaching the material with a sole instructor's limited insight to the material. Likewise, students felt more motivated to learn since the material was applicable in several areas. The engineering students could see the relationships among different fields. One student commented that, "I like how it was able to tie the Math, Electrical, and Mechanical classes I had taken thus far together into more realistic problems." Perhaps the largest and most significant difference was that the students felt an increase in their critical thinking aptitude. Gaining confidence in their ability to work or understand another discipline in some depth, the students welcomed the challenge. As one student remarked in the assessment, "I enjoyed the way that the instructor helped to relate the relevance of what we learned in nearly every lesson to real-life applications."

Using the same scale presented in Table 2, according to the student responses shown below in Figure 2 assessing course objectives, there is very good agreement on their ability to apply control theory to mechanical and electrical systems. One benefit of relating the material to both electrical and mechanical engineering disciplines is that a larger number of students may retain the material longer than if the material was taught from just one of the disciplines. Learning styles do not make as much difference as the student's prior knowledge, intelligence, and motivation $^{6}$. Again, the course has been taught for several years. We feel the administrative model and structure of the course are advantages and are in the process of assessing this organization. Better metrics will be developed to evaluate the effectiveness of this arrangement.

Dynamic Modeling and Control - Course Questions

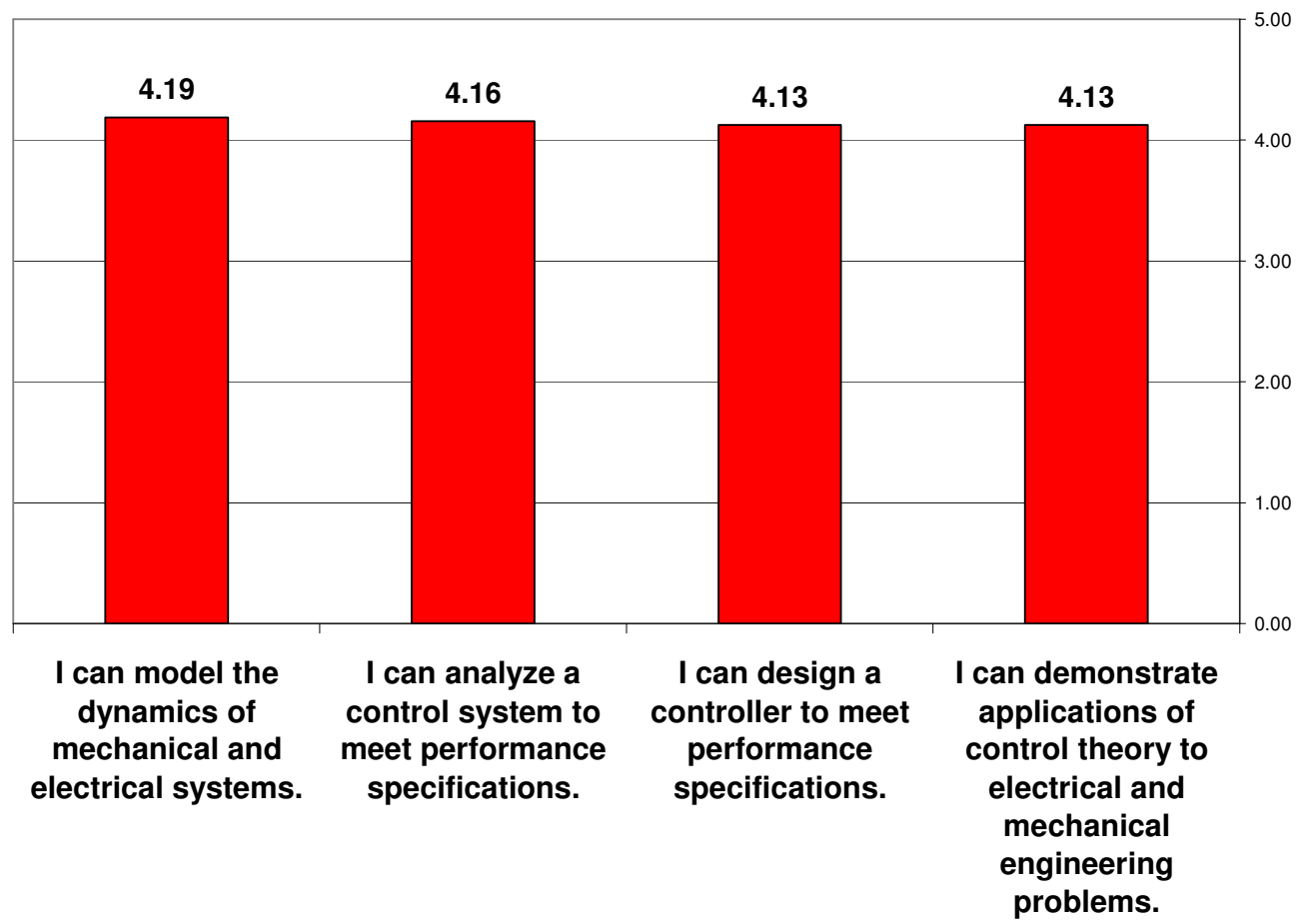

Figure 2. Course Level Survey Questions 


\section{Contributions and Future Work}

In addition to teaching a multidisciplinary course about different types of systems and integrating/generalizing systems to apply controllers, describing the advantages and limitations of this teaching initiative and endeavor provides guidelines to develop and implement other academic courses. One such course is Mechatronics, which is presently designed as a follow on course on designing electromechanical systems. It is a mostly "hands on" controls application course that is being taught for the second time at USMA. Also, this could stimulate faculty and students to approach other departments to conduct interdisciplinary research and conduct joint and collaborative design projects. Multidisciplinary projects are also highly encouraged from the stand point of the departments but also very relevant and marketable for the student's future positions.

Our short term goals are to evaluate existing course work and integrate more applications and demonstrations that could make an immediate impact to the student's learning. We intend to use this knowledge to stimulate additional interest in other departments, faculty, and students to further study dynamic modeling and controls and to encourage multidisciplinary research projects. This will better prepare our future engineers to face the multidisciplinary systems and problems that exist today.

\section{Conclusion}

The advantages, disadvantageous, and assessment of an interdisciplinary course experience extend beyond course content of both electrical engineering and mechanical engineering programs. The benefits of sharing applied engineering and math, dealing with various engineering systems, learning through generalization of problems and applying control models with different disciplines provide not only enthusiasm among students and faculty, they sustain program goals sought by the different disciplines as well as the vision of a multidisciplinary engineering study. The course profiled in this report can be mirrored elsewhere to facilitate collaboration between various engineering departments and disciplines. Nevertheless, teaching an interdisciplinary course requires a committed, motivated faculty who are creative and willing to change. Approaching a course such as Dynamic Modeling and Control is an interdisciplinary subject and experience for the faculty as well as the students, but the rewards are well worth the additional effort required to make it interesting and relevant to the students.

\section{Acknowledgement}

The views expressed herein are those of the authors and do not purport to reflect the position of the United States Military Academy, the United States Army, or the Department of Defense.

\section{Bibliography}

1. National Academy of Sciences, "Educating the Engineer of 2020: Adapting Engineering Education to the New Century", National Academies Press, Washington, D.C., 2005. 
2. Meyers, C. and Ernst, E., "NSF 95-65 Restructuring Engineering Education: A Focus on Change", NSF, Washington, D.C. 1995.

3. Davis, James R. Interdisciplinary Courses and Team Teaching. Phoenix: American Council on Education / Oryx Press Series on Higher Education, 1997.

4. Nixon, Wilfrid A. "The Challenges of Interdisciplinary Teaching." http://www.uiowa.edu/ centeach/talk/volume7/inter.html

5. "Interdisciplinary Teaching and Learning: A Panel Discussion with Stanford Faculty." Speaking of Teaching. Spring 2007 Newsletter, Vol. 16, No. 2.

6. Hughes-Hallett, Deborah. "Interdisciplinary Activities in Mathematics and Science in the United States." ZDM. Vol 30, No. 4, p. 116-118, August 1998.

7. Goetz, Karin. "Perspectives on Team Teaching." EGallery. Vol. 1, No. 4., August 2000. http://www.ucalgary.ca/ egallery/goetz.html

8. McKeachie, W. J., Pintrich, P. R., and Lin, Y-G. "Teaching Learning Strategies." Educational Psychologist, 20(3), 153-160. 1985. 